BMJ Open

Sport \&

Exercise

Medicine

\title{
Effect of Ramadan intermittent fasting on selective fitness profile parameters in young untrained Muslim men
}

\author{
Anindita Singha Roy, Amit Bandyopadhyay
}

To cite: Roy AS,

Bandyopadhyay A. Effect of Ramadan intermittent fasting on selective fitness profile parameters in young untrained Muslim men. BMJ Open Sport Exerc Med 2015;1:e000020. doi:10.1136/bmjsem-2015000020

- Prepublication history for this paper is available online. To view these files please visit the journal online (http://dx.doi.org/10.1136/ bmjsem-2015-000020).

Received 14 May 2015 Revised 29 July 2015 Accepted 2 August 2015
CrossMark

Department of Physiology, University of Calcutta, University College of Science and Technology, Kolkata, West Bengal, India

Correspondence to Dr Amit Bandyopadhyay; bamit74@yahoo.co.in

\section{ABSTRACT}

Background: The present study was aimed at investigating the effects of sleep deprivation and dietary irregularities during Ramadan intermittent fasting (RIF) on selective fitness profile parameters in young untrained male Muslim individuals.

Methods: 77 untrained Muslim men were recruited in the study. They were divided into the experimental group (EG; $n=37$, age: $22.62 \pm 1.77$ years) and the control group (CG; $n=40$, age: $23.00 \pm 1.48$ years). EG was undergoing RIF while $\mathrm{CG}$ abstained. Aerobic fitness, anaerobic capacity or high-intensity efforts (HIEs), agility, flexibility, vertical jump height and handgrip strength were measured on 8 separate occasions-15 days before RIF, 7 days before RIF, 1st day of RIF, 7th day of RIF, 15th day of RIF, 21st day of RIF, last day of RIF and 15 days after RIF.

Results: Aerobic fitness and HIE showed a significant difference $(p<0.05)$ during RIF in EG. Agility and flexibility score showed a significant decrease in $E G$ during RIF, whereas changes in the vertical jump score (VJT) and handgrip strength were statistically insignificant. Studied parameters showed an insignificant variation in CG during RIF. Aerobic fitness, HIEs, agility and flexibility showed a significant intergroup variation during different experimental trials. Conclusions: The present investigation revealed that RIF had adverse effects on aerobic fitness, HIEs, agility and flexibility of young untrained Muslims of Kolkata, India. VJT, waist-hip ratio and handgrip strength were not affected by RIF in the studied population. Mild but statistically insignificant reduction in body mass was also reflected after the mid-Ramadan week.

\section{INTRODUCTION}

More than one billion people in the world are Muslims. The major religious period of the Islamic calendar is Ramadan, which is considered as a period of purification, internal meditation and regeneration, when healthy postpubescent Muslims fast from dawn to sunset for 4 weeks. During this whole month of Ramadan intermittent fasting (RIF), they eat before dawn (Shaur meal) and after sunset (Iftar meal) without any dietary restriction and thus abstain from

\section{What are the new findings}

This is the first time that the effects of Ramadan intermittent fasting (RIF) on fitness profile parameters have been explored in an untrained population, while the earlier studies were conducted in different categories of athletes. Significant alterations in aerobic capacity, high-intensity efforts, agility and flexibility score have been reported for the first time during RIF in untrained Muslim men. Mild reduction in body weight (although statistically insignificant) was also observed for the first time in this study. This is also the first time that the 'control group' has been introduced in such a study to compare the effect of RIF in comparison to nonfasting individuals.

How might it impact on clinical practice in the near future

This study revealed that some of the fitness profile parameters deteriorated in untrained young Muslim individuals. Therefore, fitness professionals should take proper care to recommend specific training guidelines to individuals who are participating in Ramadan intermittent fasting.

food and drink intake throughout the day that may lead to nutritional and behavioural changes. $^{1-3}$ Sleep deprivation, prevalence of irritability and headaches were also increased during this month. ${ }^{23}$

During the month of Ramadan, both the food intake and sleep pattern become irregular and asymmetrical. The young Muslim men perform regular job-related physical activities that continue during the month of RIF. This might lead to a potential threat to the efficiency and safety of the concerned individuals. Hence, it is quite justified to speculate that RIF might have adverse effects on one's fitness profile. Therefore, this study was aimed at investigating the effects of RIF on selective fitness profile parameters of young untrained male Muslim individuals. 


\section{MATERIALS AND METHODS}

\section{Study protocol}

The entire study was conducted in the Sports and Exercise Physiology Laboratory, Department of Physiology, University of Calcutta, India, during 8 June to 23 August 2013. Participants visited the laboratory on eight occasions which were divided into one familiarisation trial, one preexperimental trial, five experimental trials and one postexperimental trial. The familiarisation trial, that is, the first study session, was conducted 15 days before the month of Ramadan to explain and demonstrate to the participants about the experimental requirement as well as to familiarise them with the experimental procedures. Pre-Ramadan data were collected 7 days before the month of Ramadan (pre-experimental trial). The next five sessions (ie, 1st5 th experimental trials) were conducted on the 1st, 8th, 16 th, 22nd and 30th day of the month of Ramadan. The remaining session, that is, the eighth session or postexperimental trial, was conducted 15 days after the month of Ramadan to record the post-Ramadan values of the studied fitness profile parameters.

\section{Selection of participants}

Thirty-seven young Muslim untrained male participants (mean age: $22.62 \pm 1.77$ years, mean height: 164.71 $\pm 7.76 \mathrm{~cm}$ ) who were undergoing RIF were recruited from different parts of Kolkata, India, as the experimental group (EG) of this longitudinal study. Another group of 40 untrained Muslim male participants (mean age: $23.00 \pm 1.48$ years, mean height: $165.27 \pm 4.26 \mathrm{~cm}$ ) who were not fasting during this period and not undergoing the rituals in the month of Ramadan were recruited from the same community as the control group (CG). All the participants belonged to the age group of 2025 years with similar socioeconomic background. The sample size was calculated using the method of Das and $\operatorname{Das}^{4}$ where the input of CI was set at $95 \%$. The study was conducted with 37 and 40 participants in the experimental group and CG, respectively, which was greater than the computed sample size of 32 in each group.

Other than Muslim individuals or persons engaged in regular exercise, and under medication or with any history of health complication were excluded from the study. The experimental protocol was explained and demonstrated to all of them in the familiarisation trial to allay their apprehension. Each participant signed the written informed consent form.

EG abstained from eating and drinking during all the sessions according to the religious recommendations and all of them strictly followed the religious rules of the holy month. Participants in CG maintained their normal daily activities including food and water intake but abstained from any heavy work on the days of evaluation as per the objective of the study.

The age of each participant was calculated to the nearest year from the date of birth as obtained in the birth certificate. Participants arrived in the laboratory at 9:00 on all the occasions. Body height and body mass were measured with the participants standing barefoot and wearing minimum clothing on a weighing machine fitted with a height measuring rod (Avery India Ltd, India) with an accuracy of $\pm 0.50 \mathrm{~cm}$ and $\pm 0.1 \mathrm{~kg}$, respectively.

\section{Determination of $\mathrm{V}_{2 \max }$}

Participants performed a warm-up exercise at $50 \mathrm{~W}$ intensity for a duration of $5 \mathrm{~min}$ on the Muller's magnetic brake bicycle ergometer (model of the Max-Planck Institute of Ergology, Germany). ${ }^{5}$ After that, the working intensity was increased to the first incremental intensity of $100 \mathrm{~W}$ and thereafter the intensity was increased by $20 \mathrm{~W}$ every $3 \mathrm{~min}$ until the participants stopped due to exhaustion. The criteria of exhaustion were set as:

1. A heartbeat within $10 \mathrm{bpm}$ of the age-predicted maximum heart rate;

2. A respiratory exchange ratio of more than 1.15;

3. Levelling off, that is, no further increase in oxygen uptake took place despite a further increase in work intensity, or the increase in oxygen uptake was less than $100 \mathrm{~mL} / \mathrm{min}$. The expired gas was collected at the last minute of the exercise in a Douglas bag $(150 \mathrm{~L})$ with the help of a low-resistance Collin's Triple 'J Type' valve. A wet gasometer (Toshniwal, Germany, CAT. No. CG05.10) was used to measure the volume of expired gas. A Scholander microgas analysis apparatus was used to analyse the gas samples. Maximum oxygen uptake $\left(\mathrm{VO}_{2 \max }\right)$ values were corrected to standard temperature pressure dry.

\section{Determination of HIE}

High-intensity effort (HIE) was determined by a 60 -yard dash test. ${ }^{6}{ }^{7}$ This is a ladder shuttle of progressing distances. Three marker cones were placed at the yard lines 5 yards apart. Participants started from one end, ran 5 yards and came back to the start line, then rushed immediately to the 10 yards mark and returned to the start line and finally rushed again to the 15 yards mark and returned to finish at the start line. A total of 60 yards were thus completed. In each step, the participants were asked to touch the line with their finger tips at each turn, for a total of five touches. The time taken for the entire running period was recorded by using a stopwatch.

\section{Measurement of flexibility}

Flexibility was determined by the modified sit and reach method. ${ }^{8}$ Participants sat barefoot on the floor with legs stretched out straight ahead. The soles of the feet were placed flat against a wooden box. Both the knees were locked and pressed flat to the floor. With the palms facing downwards, and the hands on top of each other or side by side, the participants tried to reach forward along the measuring line as far as possible, ensuring that the hands remained at the same level, not one reaching further forward than the other. The participants reached out and held that position for 1 or $2 \mathrm{~s}$ 
when the distance was recorded. A jerky movement of the arm or shoulder was avoided during this measurement.

\section{Determination of agility by shuttle run test}

Participants ran back and forth as fast as possible between two parallel lines which were set 30 feet apart. ${ }^{9}$ Two wooden blocks were placed behind the line opposite to the start line. The participants started the run from the start line to other line and picked up one block and returned to place it behind the start line, and then again ran to pick up the second block and returned to place it back across the start line. The time taken for the entire running period was recorded using a stop watch.

\section{Determination of VJT}

The vertical jump score (VJT) of each participant was evaluated according to the procedure elaborated in an earlier report. ${ }^{10}$ The participant chalked his fingertips and stood side on to a wall and reached up with the hand closest to the wall. Keeping the feet flat on the ground, the point of the fingertip was marked or recorded. This was the standing reach height $\left(\mathrm{M}_{1}\right)$. Then the participant jumped vertically from a static position as high as possible with the attempt to touch the wall at the highest point $\left(\mathrm{M}_{2}\right)$ of the jump. The distance between $M_{1}$ and $M_{2}$ was measured. The participant repeated the test three times with a gap of at least 10 min between the consecutive trials and the best of these three efforts was recorded.

\section{Determination of handgrip strength}

Participants hold the dynamometer in the hand to be tested, with the arm at right angles and the elbow by the side of the body. ${ }^{11}$ The base of the dynamometer rests on the first metacarpal (heel of palm), while the handle rest on the middle of four fingers. The participant pressed the dynamometer with maximum isometric effort as fast as possible (within 1-2 s) without making any movement of any other body part. The best out of three consecutive efforts with a gap of at least $3 \mathrm{~min}$ between the tests was recorded.

\section{Statistical analysis}

Data were expressed as mean $\pm \mathrm{SD}$. An unpaired twotailed $t$ test was adopted to test the significance of difference between mean values of EG and CG. Changes over time were determined by one-way repeated measure analysis of variance followed by Bonferroni post hoc analysis using SPSS V.16 software. The significance level was set at $\mathrm{p}<0.05$.

\section{RESULTS}

Values of body mass and different fitness parameters during the month of Ramadan were tabulated in table 1 . A small but statistically insignificant reduction in body mass was observed in EG, whereas in CG a mild but statistically insignificant increase in body mass was noted. Aerobic capacity and HIE showed a significant difference $(p<0.05)$ during RIF in EG, while an insignificant difference was found in CG. Agility and flexibility score showed a significant decrease during RIF in EG only, while VJT, waist circumference, hip circumference and waist-hip ratio remained unchanged in both the groups. The grip strength of both the hands in both the groups did not show any significant variation during RIF (table 2).

A significant difference in $\mathrm{VO}_{2 \max }$ was found during the month of RIF when compared between the groups. EG showed significantly lower values of agility score in comparison to CG from the midweek of RIF, that is, in the third $(\mathrm{p}<0.05)$, fourth $(\mathrm{p}<0.05)$ and fifth $(\mathrm{p}<0.001)$ experimental trials. Significant $(p<0.05)$ differences in flexibility between CG and EG were found on the 8th day (2nd experimental trial) and 30th day (5th experimental trial) of RIF. Significant intergroup variation was also observed in HIE on the 8th day (2nd experimental trial, $\mathrm{p}<0.01$ ), 22nd day (4th experimental trial, $\mathrm{p}<0.05$ ) and 30th day (5th experimental trial, $\mathrm{p}<0.05$ ) of RIF, respectively. The rest of the studied parameters did not show any significant intergroup difference during the different days of trials.

\section{DISCUSSION}

The aim of this study was to investigate the effect of RIF on fitness profile in untrained young Muslim men. This study demonstrated that RIF affected the cardiorespiratory fitness, HIEs, agility score and flexibility in the studied population. They refrained from eating and drinking throughout the day, that is, at least for 12-13 $\mathrm{h}$.

Although the hydration status has not been evaluated in this study, previous reports suggested that hypohydration could be a potential cause to reduce the physical performance during RIF and a mild to moderate level of hypohydration changes in the high-intensity exercise and muscle power. ${ }^{12-14}$ Prolonged food and fluid deprivation might be responsible for dehydration and metabolic changes which could be attributed to the alteration in individual performance during different days of RIF in this present study. Similar findings were also reported in earlier studies. ${ }^{15} 16$

Sleep loss or deprivation during the month of Ramadan might also be another causative factor for alteration in some of the fitness profile parameters in the studied population. It is a limitation that the sleep pattern of the presently studied population was not monitored during the period of investigation. Bahammam ${ }^{17}$ documented that sleep time was delayed in the first and third weeks of Ramadan compared with the regular month, and such delays in bedtime were coupled with a constant wake-up time which produced daytime fatigue. Disturbed and intermittent (wake up before dawn to eat, and return to sleep) night sleep was also reported during the month of Ramadan, which in turn resulted 
Table 1 Physical and fitness parameters of the studied population during the different days of RIF

\begin{tabular}{|c|c|c|c|c|c|c|c|}
\hline \multirow[b]{2}{*}{ Parameters } & \multirow[b]{2}{*}{$\begin{array}{l}\text { Pre-experimental trial } \\
\text { ( } 7 \text { days before RIF) }\end{array}$} & \multicolumn{5}{|c|}{ During the month of RIF } & \multirow[b]{2}{*}{$\begin{array}{l}\text { Postexperimental trial } \\
\text { (15 days after RIF) }\end{array}$} \\
\hline & & $\begin{array}{l}\text { First } \\
\text { experimental } \\
\text { trial (1st day) }\end{array}$ & $\begin{array}{l}\text { Second } \\
\text { experimental trial } \\
\text { (8th day) }\end{array}$ & $\begin{array}{l}\text { Third } \\
\text { experimental trial } \\
\text { (16th day) }\end{array}$ & $\begin{array}{l}\text { Fourth } \\
\text { experimental trial } \\
\text { (22nd day) }\end{array}$ & $\begin{array}{l}\text { Fifth } \\
\text { experimental trial } \\
\text { (30th day) }\end{array}$ & \\
\hline CG & $55.80 \pm 7.23$ & $55.93 \pm 7.54$ & $56.30 \pm 7.36$ & $56.45 \pm 7.37$ & $56.75 \pm 8.09$ & $56.94 \pm 7.87$ & $56.37 \pm 7.82$ \\
\hline$E G$ & $56.43 \pm 9.25$ & $56.35 \pm 9.56$ & $56.34 \pm 9.83$ & $56.12 \pm 9.70$ & $55.69 \pm 9.96$ & $55.20 \pm 9.94$ & $56.19 \pm 9.51$ \\
\hline \multicolumn{8}{|l|}{$W C(\mathrm{~cm})$} \\
\hline CG & $31.78 \pm 2.56$ & $32 \pm 2.55$ & $31.96 \pm 2.22$ & $32.03 \pm 2.01$ & $31.79 \pm 2.33$ & $32.18 \pm 2.07$ & $31.91 \pm 2.20$ \\
\hline $\mathrm{CG}$ & $34.73 \pm 2.36$ & $34.54 \pm 1.89$ & $34.35 \pm 1.93$ & $34.59 \pm 1.96$ & $34.47 \pm 1.91$ & $34.68 \pm 1.77$ & $34.05 \pm 2.06$ \\
\hline EG & $34.61 \pm 2.34$ & $34.33 \pm 2.39$ & $34.55 \pm 2.12$ & $34.61 \pm 2.07$ & $34.56 \pm 1.98$ & $34.45 \pm 2.30$ & $34.12 \pm 2.61$ \\
\hline \multicolumn{8}{|l|}{$\mathrm{W}-\mathrm{H}$ ratio } \\
\hline CG & $0.92 \pm 0.05$ & $0.93 \pm 0.05$ & $0.93 \pm 0.05$ & $0.92 \pm 0.03$ & $0.92 \pm 0.04$ & $0.93 \pm 0.04$ & $0.94 \pm 0.03$ \\
\hline$E G$ & $0.91 \pm 0.07$ & $0.92 \pm 0.06$ & $0.91 \pm 0.06$ & $0.91 \pm 0.06$ & $0.90 \pm 0.06$ & $0.90 \pm 0.07$ & $0.91 \pm 0.05$ \\
\hline \multicolumn{8}{|l|}{ VJT (inch) } \\
\hline CG & $14.45 \pm 2.53$ & $14.81 \pm 2.63$ & $14.76 \pm 2.54$ & $14.86 \pm 2.66$ & $14.91 \pm 2.57$ & $14.79 \pm 2.61$ & $14.50 \pm 2.39$ \\
\hline EG & $14.22 \pm 3.22$ & $14.13 \pm 2.80$ & $13.81 \pm 3.53$ & $14.35 \pm 3.33$ & $14.59 \pm 3.46$ & $14.05 \pm 3.10$ & $14.62 \pm 3.10$ \\
\hline EG & $4.30 \pm 1.82$ & $4.42 \pm 2.04$ & $5.26 \pm 2.53 \#^{*}$ & $4.96 \pm 2.33$ & $4.86 \pm 2.31$ & $5.43 \pm 2.27 \#^{*}$ & $4.49 \pm 1.80$ \\
\hline \multicolumn{8}{|c|}{$\mathrm{VO}_{2 \max }(\mathrm{mL} / \mathrm{kg} / \mathrm{min})$} \\
\hline $\mathrm{CG}$ & $43.73 \pm 5.13$ & $43.99 \pm 4.68$ & $44.96 \pm 4.84$ & $44.07 \pm 4.43$ & $43.77 \pm 4.91$ & $44.25 \pm 3.94$ & $44.05 \pm 4.91$ \\
\hline$E G$ & $44.02 \pm 5.24$ & $41.19 \pm 6.06 \#^{*}$ & $39.23 \pm 4.41^{\star \star \star}$ & $36.34 \pm 4.47 \#^{\star * *}$ & $34.80 \pm 3.86 \#^{\star \star \star}$ & $34.15 \pm 4.66 \#^{\star \star \star}$ & $43.57 \pm 5.02$ \\
\hline \multicolumn{8}{|c|}{ HIE (seconds) } \\
\hline CG & $7.94 \pm 0.83$ & $7.89 \pm 0.87$ & $8.16 \pm 0.78$ & $7.90 \pm 0.84$ & $7.89 \pm 0.85$ & $8.21 \pm 0.92$ & $7.94 \pm 0.90$ \\
\hline$E G$ & $7.67 \pm 1.95$ & $7.25 \pm 1.65 \#^{\star \star}$ & $7.69 \pm 1.45$ & $7.85 \pm 1.51$ & $8.45 \pm 1.43 \#^{*}$ & $8.68 \pm 1.42^{*}$ & $7.76 \pm 1.92 \#$ \\
\hline
\end{tabular}

Values are mean \pm SD.

One-way repeated measure ANOVA shows significant difference at the level of $p<0.05(\# p<0.05)$

Results of $t$ test ${ }^{*} p<0.05,{ }^{* *} p<0.01,{ }^{* * *} p<0.001$ (when compared between the control and experimental groups on a specific visit).

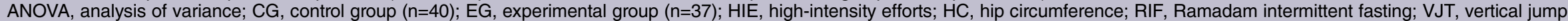
score; $\mathrm{VO}_{2 \max }$, maximum oxygen uptake; $\mathrm{WC}$, waist circumference; $\mathrm{W}-\mathrm{H}$ ratio, waist to hip ratio.

$746 ! 1$ रdoo ka 
Table 2 Handgrip strength of the studied population during the different days of RIF

\begin{tabular}{|c|c|c|c|c|}
\hline \multirow[b]{2}{*}{ Trial } & \multicolumn{4}{|c|}{ Hand grip strength (N) } \\
\hline & VR & VL & HR & HL \\
\hline \multicolumn{5}{|c|}{ Pre-experimental trial (7 days before RIF) } \\
\hline CG & $301.55 \pm 37.36$ & $309.40 \pm 47.66$ & $304.30 \pm 36.58$ & $304 \pm 42.07$ \\
\hline EG & $294.49 \pm 55.02$ & $30.68 \pm 64.14$ & $291.06 \pm 53.74$ & $300.87 \pm 48.84$ \\
\hline \multicolumn{5}{|c|}{ 1st experimental trial (1st day) } \\
\hline $\mathrm{CG}$ & $309.69 \pm 38.34$ & $314.11 \pm 46.48$ & $306.26 \pm 43.74$ & $312.83 \pm 34 . .62$ \\
\hline $\mathrm{EG}$ & $310.09 \pm 51.39$ & $315.19 \pm 49.72$ & $309.30 \pm 51.29$ & $313.81 \pm 41.38$ \\
\hline \multicolumn{5}{|c|}{ 2nd experimental trial (8th day) } \\
\hline CG & $308.22 \pm 43.93$ & $315.09 \pm 42.17$ & $310.18 \pm 42.86$ & $312.63 \pm 38.25$ \\
\hline EG & $296.85 \pm 51.78$ & $309 \pm 55.02$ & $303.22 \pm 45.01$ & $308.03 \pm 52.47$ \\
\hline \multicolumn{5}{|c|}{ 3rd experimental trial (16th day) } \\
\hline CG & $311.36 \pm 43.64$ & $319.70 \pm 45.70$ & $309.40 \pm 44.62$ & $313.62 \pm 36.68$ \\
\hline$E G$ & $299.79 \pm 57.27$ & $307.14 \pm 56.88$ & $299.79 \pm 55.60$ & $299.99 \pm 51.78$ \\
\hline \multicolumn{5}{|c|}{ 4th experimental trial (22nd day) } \\
\hline CG & $302.54 \pm 43.25$ & $311.36 \pm 50.21$ & $298.42 \pm 46.09$ & $307.73 \pm 41.48$ \\
\hline$E G$ & $297.93 \pm 52.37$ & $310.09 \pm 59.04$ & $303.22 \pm 58.45$ & $301.36 \pm 50.41$ \\
\hline \multicolumn{5}{|c|}{ 5th experimental trial (30th day) } \\
\hline $\mathrm{CG}$ & $302.54 \pm 41.48$ & $311.46 \pm 49.62$ & $295.67 \pm 41.19$ & $306.75 \pm 45.40$ \\
\hline EG & $296.55 \pm 51.58$ & $305.38 \pm 54.82$ & $304.50 \pm 55.80$ & $299.79 \pm 55.88$ \\
\hline \multicolumn{5}{|c|}{ Postexperimental trial (15 days after RIF) } \\
\hline CG & $301.06 \pm 40.70$ & $312.64 \pm 41.38$ & $290.57 \pm 45.52$ & $304.99 \pm 40.60$ \\
\hline $\mathrm{EG}$ & $295.77 \pm 50.11$ & $292.83 \pm 53.54$ & $284.88 \pm 50.70$ & $293.12 \pm 48.35$ \\
\hline
\end{tabular}

lethargy and altered cognitive function which might have played an important role to affect the fitness profile parameters in the studied population. ${ }^{2}$

\section{Body mass}

A small reduction in body mass during RIF was noticed in this study, although the difference was not statistically significant as also reported by Ramadan ${ }^{15}$ and Fenneni et $a .^{18}$ This finding was contradictory to the earlier findings which reported a significant change in body mass during the month of Ramadan. ${ }^{19-21}$ The explanation behind the contradictory findings might be the difference in food habits, geographical and social environment which perhaps influenced the energy balance and might have contributed to the inconsistency of the findings of the different studies. Although it is a major limitation that the data on food habits and energy intake were not monitored, significantly higher energy intake during RIF was reported by Frost and Pirani, ${ }^{22}$ whereas Beltaifa et $a l^{23}$ documented that daily energy intake did not significantly differ before, after and during Ramadan. The food and fluid intake during RIF was only restricted from dawn to sunset and people were allowed to take plenty of food and water from sunset to dawn without any restriction to the quantity. ${ }^{2}$ Meckel et $a l^{2}$ reported that reduced carbohydrate consumption during RIF might be the contributory factor towards reduced muscle glycogen store that in turn might be one of the responsible factors towards the decrease in body mass. ${ }^{2}$ According to Fenneni $e t$ al, ${ }^{18}$ the insignificant change of body mass during RIF in both the groups (EG and CG) might be most likely due to the fact that the fat-free mass did not change during the study (although it is a limitation that the fat-free mass was not categorically measured in this study). On the other hand, a decrease in powerful performances during RIF was attributed to the decrease in fat-free mass. ${ }^{24} 25$

\section{Maximum oxygen uptake}

$\mathrm{VO}_{2 \max }$ represents one's cardiorespiratory fitness. This study depicted a significant decrease in mean value of $\mathrm{VO}_{\text {2max }}$ following RIF which indicated a significant reduction in aerobic capacity as well as in cardiorespiratory fitness in EG. This finding corroborated with earlier reports. $^{2}{ }^{26}{ }^{27}$ However, CG did not show any significant variation in $\mathrm{VO}_{2 \max }$ during the entire course of the study. $\mathrm{VO}_{2 \max }$ values in $\mathrm{EG}$ were significantly lower than those in CG in the five experimental trials conducted during the month of Ramadan, although pre-Ramadan and post-Ramadan trials did not show any intergroup difference in $\mathrm{VO}_{2 \max }$. Previous studies failed to find any negative effect of RIF on the aerobic capacity of sedentary adults, but a reduction in heart rate and ventilatory responses to submaximal exercise were reported during RIF. $^{28}$ Though it is a limitation of the present investigation that biochemical parameters were not measured, several studies reported an increase in serum concentration of protein, urea, uric acid, sodium and chloride during RIF. These changes during RIF indicated muscle 
damage, dehydration and catabolism in the participants and that might be a major cause of significant reduction in aerobic power during RIF. ${ }^{26-28}$ Earlier reports indicated that metabolism of the body slows down in the daytime during the month of Ramadan. ${ }^{27}$ A decrease in venous return and inhibition of catecholamine release have also been reported during RIF and these factors lead to a decrease in sympathetic tone causing a decrease in blood pressure, heart rate and cardiac output, which in turn affect the physical work capacity and aerobic capacity during this fasting month. ${ }^{29} 30$ Reduction in glycolytic capacity and a slower replenishment of muscle creatine phosphate store during the exercise might also be contributory factors towards a decrease in aerobic capacity of the fasting participants. ${ }^{2}$ Decreased carbohydrate consumption during RIF might be a contributory factor towards reduced muscle glycogen store and affects the performance. ${ }^{2}$

\section{HIE and VJT}

Sixty-yard dash time was significantly increased in the different phases of RIF and that indicated a significant decrease in HIE in this study. Significant intergroup variation was also observed in HIE on the 8th day (2nd experimental trial, $\mathrm{p}<0.01)$, 22nd day (4th experimental trial, $\mathrm{p}<0.05$ ) and 30th day (5th experimental trial, $\mathrm{p}<0.05)$ of RIF, respectively. VJT did not show any alteration in EG and CG during RIF. This finding is contradictory to the earlier report of Meckel et at but corroborated with the findings of Chaouachi $e t a l^{3}$ and Karli $e t a l^{31}$ who reported no significant change in single effort jump, countermovement jump and multiple effort jump which assess the HIE of an individual. Chtourou et $a \vec{l}^{2}$ reported an insignificant change in the HIE when it was measured in the morning session of RIF, but a decrease in HIE was found when it was measured in the evening session. No intergroup variation in VJT was noted in any of the trials. The reduction in HIE in EG during RIF might be due to the loss of body mass and low carbohydrate intake, which caused a reduction in muscle buffering capacity during intense muscle contractions. ${ }^{3}{ }^{31}$ Previous studies established that carbohydrate intake decreases significantly during RIF along with irregular timing of food intake, which perhaps led to decreased muscle glycogen stores that might have altered the HIE in this study. ${ }^{33} 34$

\section{Flexibility and agility}

Flexibility and agility showed a significant reduction in $\mathrm{CG}$, as was also reported by Zerguini et al. ${ }^{1}$ On the other hand, Gutierrez et $a l^{35}$ found that the agility score remained unchanged during the fasting period. Agility score was significantly lower in EG during the third $(p<0.05)$, fourth $(p<0.05)$ and fifth $(p<0.001)$ experimental trials in comparison to CG. Significant $(p<0.05)$ differences in flexibility between CG and EG were found on the 8th day (2nd experimental trial) and 30th day (5th experimental trial) of RIF. The rest of the studied parameters did not show any significant intergroup difference during the different days of trials. Agility and flexibility were mainly influenced by skill, neuromuscular control and the participant's coordination. ${ }^{2}$ The literature revealed that sleep deprivation occurs during RIF at night, ${ }^{17}$ which alters the participant's coordination, alertness and skill control. ${ }^{26} \quad 3637$ Reilly and Waterhouse $^{38}$ concluded that sleep loss produced a direct effect on muscle activity and that it also had an indirect effect on physical performance via changes in mental performance, coordination and motivation. So it might be possible that the altered coordination and skill control could not contribute to overcoming any metabolic decrement leading to a significant decrease in agility and flexibility score among the fasting participants in this study.

\section{Handgrip strength}

Gutierrez $e t a l^{5}$ reported insignificant variation in the handgrip strength during RIF as was also observed in this study. Grip strength of both the hands in vertical and horizontal positions was higher than that of the healthy Indians of Amritsar but lower than that of the healthy Australian, British and American populations. ${ }^{39-42}$ Such a population-wise variation in handgrip strength might be attributed to the hypothesis that handgrip strength is highly affected by height, mass, body size hand length, etc. ${ }^{43}$ The exact reason for unaltered handgrip strength in this study is not clear yet.

\section{CONCLUSION}

The present investigation revealed that RIF had adverse effects on the aerobic fitness, HIEs, agility and flexibility of young untrained Muslims of Kolkata, India. A mild but statistically insignificant reduction in body mass was also reflected in the study after the mid-Ramadan week However, VJT, waist-hip ratio and handgrip strength were not affected by RIF in the studied population.

Acknowledgements The authors acknowledge the cooperation of the participants who volunteered in the study.

Contributors ASR was involved in the planning and design of the research protocol; acquisition, analysis or interpretation of data; and drafting the work or revising it critically for important intellectual content. $A B$ provided substantial contributions to the conception or design of the work; and was involved in the planning and design of the research protocol; data collection, analysis and interpretation; preparing and revising the manuscript; and final approval of the version published.

\section{Competing interests None declared.}

Ethics approval Human Ethical Committee of the Department of Physiology, University of Calcutta.

Provenance and peer review Not commissioned; externally peer reviewed.

Open Access This is an Open Access article distributed in accordance with the Creative Commons Attribution Non Commercial (CC BY-NC 4.0) license, which permits others to distribute, remix, adapt, build upon this work noncommercially, and license their derivative works on different terms, provided the original work is properly cited and the use is non-commercial. See: http:// creativecommons.org/licenses/by-nc/4.0/ 


\section{REFERENCES}

1. Zerguini $\mathrm{Y}$, Kirkendall D, Junge A, et al. Impact of Ramadan on physical performance in professional soccer players. Br J Sports Med 2007;41:398-400.

2. Meckel Y, Ismaeel A, Eliakim A. The effect of the Ramadan fast on physical performance and dietary habits in adolescent soccer players. Eur J Appl Physiol 2008;102:651-7.

3. Chaouachi A, Coutts AJ, Chamari K, et al. Effect of Ramadan intermittent fasting on aerobic and anaerobic performance and perception of fatigue in male elite judo athletes. J Strength Cond Res 2009;23:2702-9.

4. Das D, Das A. Statistics in biology and psychology. Calcutta: Academic Publisher, 1998:252.

5. Bandyopadhyay A. Modification of the Fox method to predict maximum oxygen uptake in female university student of Kolkata India. J Hum Ergol 2011;40:73-7.

6. Barrow HM. The test of motor ability for college Men. Res $Q$ 1954;25:253.

7. Chamari K, Padulo J. 'Aerobic' and 'anaerobic' terms used in exercise physiology: a critical terminology reflection. Sports Med Open 2015;1:9.

8. Wells KF, Dillon EK. The sit and reach, a test of back and leg flexibility. Res Q 1952;23:115.

9. Aahperd. Youth fitness test manual. Washington DC. American Alliaence for Health, Physical Education and Recreation, 1976:32, $40,48$.

10. Chatterjee $\mathrm{S}$, Chatterjee $\mathrm{P}$, Mukherjee PS, et al. Vertical jump test on school going boys and girls. Ind J Physiol Allied Sci 2004;58:66-9.

11. Bandyopadhyay A. Body composition and hand grip strength in male brick field workers. Malays J Med Sci 2008;15:47-52.

12. Barr SI. Effects of dehydration on exercise performance. Can J Appl Physiol 1999;24:164-7.

13. Judelson DA, Maresh CM, Anderson JM, et al. Hydration and muscular performance: does fluid balance affect strength, power and high-intensity endurance? Sports Med 2007;37:907-21.

14. Chaouachi A, Leiper JB, Souissi N, et al. Effects of Ramadan intermittent fasting on sports performance and training: a review. Int J Sports Physiol Perform 2009;4:419-34.

15. Ramadan J. Does fasting during Ramadan alter body composition, blood constituents and physical performance? Med Princ Pract 2002;11(Suppl 2):41-6

16. El Ati J, Beji C, Danguir J. Increased fat oxidation during Ramadan fasting in healthy women: an adaptative mechanism for body weight maintenance. Am J Clin Nutr 1995;62:302-7.

17. Bahammam A. Does Ramadan fasting affect sleep? Int $J$ Clin Pract 2006;60:1631-7.

18. Fenneni MA, Latiri I, Aloui A, et al. Effects of Ramadan on physical capacities of North African boys fasting for the first time. Libyan $J$ Med 2014;9:25391.

19. Ramadan J, Telahoun G, Al-Zaid NS, et al. Responses to exercise, fluid and energy balance during Ramadan in sedentary and active males. Nutrition 1999;15:735-9.

20. Husain R, Duncan MT, Cheah SH, et al. Effect of fasting in Ramadan on tropical Asiatic Moslems. Br J Nutr 1987;58:41-8.

21. Ziaee V, Razaei M, Ahmadinejad Z, et al. The changes of metabolic profile and weight during Ramadan fasting. Singapore Med $J$ 2006:47:409-14.

22. Frost G, Pirani S. Meal frequency and nutritional intake during Ramadan: a pilot study. Hum Nutr Appl Nutr 1987;41:47-50.
23. Beltaifa L, Bouguerra R, Ben Salma C, et al. Food intake and anthropometrical and biological parameters in adult Tunisians during fasting at Ramadan. East Mediterr Health J 2002;8:603-11.

24. Chaouachi A, Leiper JB, Chtourou $\mathrm{H}$, et al. The effects of Ramadan intermittent fasting on athletic performance: recommendations for the maintenance of physical fitness. J Sports Sci 2012;30:53-73.

25. Aloui A, Chtourou $\mathrm{H}$, Souissi $\mathrm{N}$, et al. Ramadan fasting and sport performance. In: Chtourou $\mathrm{H}$, ed. Effects of Ramadan fasting on health and athletic performance. OMICS Group eBooks, 2013:2-8

26. Roky R, Houti I, Moussamih S, et al. Physiological changes during Ramadan intermittent fasting. Ann Nutr Metab 2004;48:296-303.

27. Sweileh N, Schnitzler A, Hunter GR, et al. Body composition and energy metabolism in resting and exercising Muslims during Ramadan fast. J Sports Med Phys Fitness 1992;32:156-63.

28. Ramadan J, Barac-Nieto M. Cardio-respiratory responses to moderately heavy aerobic exercise during the Ramadan fasts. Saudi Med J 2000;21:238-44.

29. Suwaidi AJ, Bener A, Gehani AA, et al. Does the circadian pattern for acute cardiac events presentation vary with fasting? J Postgrad Med 2006;52:30-3.

30. Stokholm KH, Breum L, Astrup L. Cardiac contractility, central hemodynamics and blood pressure regulation during semistarvation Clin Physiol 1991:11:513-23.

31. Karli U, Guvenc A, Aslan A, et al. Influence of Ramadan fasting on anaerobic performance and recovery following short time high intensity exercise. J Sports Sci Med 2007;6:490-7.

32. Chtourou $\mathrm{H}$, Hammouda $\mathrm{O}$, Chaouachi $\mathrm{A}$, et al. The effect of time-of-day and Ramadan fasting on anaerobic performances. Int $\mathrm{J}$ Sports Med 2012;33:142-7.

33. Burke LM, Cox GR, Culmmings NK, et al. Guidelines for daily intake: do athletes achieve them? Sports Med 2001;31:267-99.

34. Jeukendrup AE. Carbohydrate intake during exercise and performance. Nutrition 2004;20:669-77.

35. Gutierrez A, Gonzalez-Gross M, Delgado M, et al. Three days fast in sportsmen decreases physical work capacity but not strength or perception-reaction time. Int J Sport Nutr Exerc Metab 2001;11:420-9.

36. Roky R, Iraki L, Hajkhlifa R, et al. Daytime alertness, mood, psychomotor performances, and oral temperature during Ramadan intermittent fasting. Ann Nutr Metab 2000;44:101-7.

37. Kirkendall DT, Chaouachi A, Aziz AR, et al. Strategies for maintaining fitness and performance during Ramadan. J Sports Sci 2012;30(Suppl 1):S103-8.

38. Reilly T, Waterhouse J. Sports performance: is there evidence that the body clock plays a role? Eur J Appl Physiol 2009;106:321-32.

39. Koley S, Melton S. Age-related changes in handgrip strength among healthy Indian males and females aged 6-25years. J Life Sci 2010;2:73-80.

40. Massy-Westropp NM, Gill TK, Taylor AW, et al. Hand grip strength: age and gender stratified normative data in a population-based study. BMC Res Notes 2011;4:127-31.

41. Gilbertson L, Barber-Lomax S. Power and pinch grip strength recorded using the hand-held Jamar dynamometer and $\mathrm{B}+\mathrm{L}$ hydraulic pinch gauge: British normative data for adults. $\mathrm{Br} J$ Occup Ther 1994;57:483-8.

42. Bear-Lehman J, Miller PA, Adler M, et al. An exploration of hand strength and sensation in community elders. Top Geriatr Rehabil 2003;19:127-36.

43. Koley S, Singh AP. An association of dominant hand grip strength with some anthropometric variables in Indian collegiate population. Anthropol Anz 2009;67:21-8. 